\title{
Qualidade das anotações de enfermagem relacionadas à ressuscitação cardiopulmonar comparadas ao modelo Utstein*
}

\author{
Quality of nursing records related to cardiopulmonary resuscitation compared to the Utstein model
}

\author{
Calidad de las anotaciones de enfermería relacionadas a la resucitación cardiopulmonar comparadas \\ con el modelo Utstein
}

\author{
Ana Paula Fernandes ${ }^{1}$, Cássia Regina Vancini ${ }^{2}$, Frederico Cohrs ${ }^{3}$, Rita Simone \\ Lopes Moreira ${ }^{4}$
}

\section{RESUMO}

Objetivo: Analisar a qualidade das anotações de enfermagem relacionadas à ressuscitação cardiopulmonar, comparando-as ao protocolo validado Utstein, em um hospital universitário. Métodos: Estudo retrospectivo, exploratório, descritivo, de abordagem quantitativa, realizado por meio de consulta a prontuários de pacientes que sofreram parada cardiorrespiratória (PCR) seguida de óbito. A coleta de dados foi realizada no período de $1^{\circ}$ de maio a 30 de junho de 2009. Resultados: Dos 144 prontuários consultados, 74 foram dispensados por não haver nenhuma informação registrada dos itens a serem estudados e, 70 constituíram a amostra do estudo. Nestes, não havia anotações referentes à causa imediata da PCR (92\%), intervenções realizadas na tentativa de recuperação cardiorrespiratória (RCP) (71\%), ritmo inicial de PCR (59\%), hora dos eventos (16\%), drogas utilizadas (50\%) e profissionais envolvidos na RCP (88\%). Conclusões: As anotações foram escassas e, frequentemente, não realizadas. A utilização do modelo Utstein favorece a anotação sequencial dos eventos, evitando a perda de dados.

Descritores: Parada cardiorrespiratória; Registros de Enfermagem; Óbito; Protocolos

\begin{abstract}
Objective: To assess the quality of nursing records related to cardiopulmonary resuscitation, comparing them to the validated Utstein protocol, in a university hospital. Methods: Retrospective, exploratory and descriptive study, with quantitative approach, performed by means of consultation records of patients that suffered cardiorespiratory arrest (CRA) followed by death. The data collection was carried out in the period of May 1st to June 30 ${ }^{\text {th }}$, in 2009. Results: Of the 144 medical records surveyed, 74 were dismissed for not having any recorded information on the items to be studied and, 70 constituted the study sample. In these there were no entries on: the immediate cause of CRA ( $92 \%$ ); the interventions seeking to recover the cardiorespiratoy arrest (RCA) (71\%); on the initial rate of CRA (59\%); on the time of events (16\%); on drugs used $(50 \%)$; and, on the professionals involved in RCA (88\%). Conclusions: The notes were scarce and often not realized. The use of the Utstein model favors the annotation sequence of events, avoiding data loss.
\end{abstract}

Keywords: Cardiopulmonary arrest; Nursing records; Death; Protocols

\section{RESUMEN}

Objetivo: Analizar la calidad de las anotaciones de enfermería relacionadas a la resucitación cardiopulmonar, comparándolas con el protocolo validado Utstein, en un hospital universitario. Métodos: Estudio retrospectivo, exploratorio, descriptivo, de abordaje cuantitativo, realizado por medio de consulta a fichas de pacientes que sufrieron parada cardiorespiratoria (PCR) seguida de muerte. Los datos fueron recolectados en el período de $1^{\circ}$ de mayo a 30 de junio de 2009. Resultados: Entre las 144 fichas consultadas, 74 fueron liberadas por no haber ninguna información registrada de los ítems a ser estudiados y, 70 constituyeron la muestra del estudio. En estas, no habían anotaciones sobre la causa inmediata de la PCR (92\%), intervenciones realizadas tratando de recuperar la parada cardiorespiratoria (RPC) (71\%), ritmo inicial de PCR (59\%), hora de los eventos (16\%), drogas utilizadas (50\%) y profesionales envueltos en la RPC (88\%). Conclusiones: Las anotaciones fueron escasas y, frecuentemente, no realizadas. La utilización del modelo Utstein favorece la anotación secuencial de los eventos, evitando la pérdida de datos.

Descriptores: Parada cardiorrespiratoria; Registros de Enfermería; Muerte; Protocolos

\footnotetext{
* Trabalho extraído da Monografia de Conclusão de Curso da Graduação em Enfermagem da Universidade Federal de São Paulo - UNIFESP - São Paulo (SP), Brasil. ${ }^{1}$ Enfermeira residente no Programa de Residência Multiprofissional da Universidade Federal de São Paulo - UNIFESP.

${ }^{2}$ Enfermeira do Departamento de Enfermagem, Disciplina de Fundamentos de Enfermagem e Enfermagem Médico-cirúrgica da Universidade Federal de São Paulo - UNIFESP - São Paulo (SP), Brasil.

${ }_{3}^{3}$ Analista de informação. Pós-graduando (Mestrado) do Departamento de Medicina Preventiva da Universidade Federal de São Paulo - UNIFESP - São Paulo (SP), Brasil.

${ }^{4}$ Pósgraduanda (Doutorado) do Programa de Pós-Graduação em Medicia (Cardiologia) da Universidade Federal de São Paulo- - UNIFESP - São Paulo (SP), Brasil.
} 


\section{INTRODUÇÃO}

A parada cardiorrespiratória (PCR) é caracterizada pela ausência de responsividade, apneia ou respiração agônica e ausência de atividade mecânica cardíaca, confirmada por pulso não detectável ${ }^{(1)}$.

Os distúrbios do ritmo mais comumente encontrados nas situações de PCR são: Fibrilação Ventricular (FV), Taquicardia Ventricular sem pulso (TV), Atividade Elétrica sem Pulso (AESP) e Assistolia. As duas primeiras modalidades acontecem com maior frequência no ambiente extra-hospitalar, e as duas últimas, geralmente, ocorrem no ambiente intra-hospitalar ${ }^{(2)}$. Durante a última década do século XXI, houve um aumento marcante na promoção de programas de treinamento em ressuscitação cardiopulomonar (RCP), seguindo as diretrizes do Royal College of Physicians ${ }^{(3)}$, no que resulta em um aumento dos custos financeiros, com pequeno ou nenhum benefício ao paciente ${ }^{(4-5)}$.

Apesar da RCP intra-hospitalar possuir baixo impacto na diminuição da mortalidade ${ }^{(3)}$, alguns fatores devem ser considerados, tais como as características dos pacientes hospitalizados, que, muitas vezes, estão em situação grave, com afecções multissistêmicas, doenças de prognóstico ruim ou doenças crônicas em fase final ${ }^{(4)}$.

Entretanto, conhece-se pouco sobre a eficácia da RCP intra-hospitalar, pois os resultados observados em estudos publicados variam de maneira extrema, desde os tipos de populações estudadas até as nomenclaturas e definições das variáveis mensuradas ${ }^{(6)}$. Ademais, alguns estudos revelam que a demografia local, as causas do colapso e outros fatores podem afetar o resultado da $\operatorname{RCP}^{(7)}$. Em razão desse fato, no início dos anos de 1990, em conferência na antiga cidade de Utstein, na Noruega, foi criado um modelo de registro para a PCR, denominado "Utstein Style»(6).

A criação desse modelo teve como objetivo a padronização dos registros de atendimento a pacientes em PCR, a fim de obter uma comparação adequada entre os resultados dos esforços de RCP, com definições e metodologia uniformes. A partir daí, muitas instituições têm adotado a nomenclatura Utstein, para registrar, de maneira sistemática, as manobras de RCP e os resultados obtidos $^{(8)}$.

A equipe de enfermagem é formada por profissionais que ficam grande parte do tempo próximos ao paciente, sobretudo dos criticamente doentes, sendo de suma importância que saibam agir em situações de emergência, como nos casos de PCR. O enfermeiro, frequentemente, é o responsável pela realização da avaliação primária e pelo início das manobras de $\mathrm{RCP}^{(9)}$. Sendo assim, deve registrar essas informações de maneira completa e detalhada, o que exige conhecimento, competência e disponibilidade desse profissional ${ }^{(10)}$.
As anotações de enfermagem atendem aos aspectos da Lei do Exercício Profissional n. 7.498/86, devendo ser claras, concisas, objetivas, pontuais e cronológicas, descrevendo as observações efetuadas e tratamentos ministrados ao cliente ${ }^{(10)}$. Desta maneira, todas as atividades e procedimentos realizados pelos profissionais de enfermagem devem constar do prontuário do paciente, sendo passíveis de processo ético legal a sua não realização por esses profissionais. Além disso, as anotações realizadas pela equipe de enfermagem fornecem suporte para a evolução de enfermagem, por meio da reflexão a respeito dos cuidados prestados e respectivas respostas do paciente, comparando-se aos resultados esperados ${ }^{(10)}$.

O registro dos procedimentos realizados pelo enfermeiro durante o atendimento à PCR, é fundamental, para que sejam avaliados sinais e sintomas iniciais, a sequência e eficácia da assistência prestada, a evolução clinica, mediante as ações realizadas, garantindo, desse modo, a segurança e o respaldo legal seja para o paciente, seja para o profissional. A escassez dos registros de enfermagem além de desvalorizar as atividades dos profissionais envolvidos nesse atendimento, também o fragilizam quando da ocorrência de ação por erros e danos impetrados por familiares. Destaca-se também o prejuízo quanto à realização de estudos nessa temática e a avaliação do atendimento.

Desta maneira, a análise da qualidade das anotações de enfermagem é indispensável, por ser um meio de informação e registro ordenado, efetuado pela equipe de enfermagem, sendo um valioso instrumento para avaliar a qualidade de sua atuação e a importância de sua presença no momento do atendimento ${ }^{(10-11)}$.

\section{OBJETIVO}

Analisar a qualidade das anotações de enfermagem relacionadas à ressuscitação cardiopulmonar, comparando-as ao protocolo validado Utstein, em um hospital universitário.

\section{MÉTODOS}

Trata-se de um estudo retrospectivo, exploratório e descritivo, com abordagem quantitativa. O estudo foi realizado por meio de consulta nos prontuários encaminhados ao Serviço de Arquivo Médico e Estatístico de um hospital de nível terciário, de grande porte, universitário, localizado na região metropolitana de São Paulo - SP.

O universo da pesquisa constituiu-se de 144 prontuários de pacientes que apresentaram PCR seguida de óbito, no período de 1 de dezembro de 2008 a 28 de fevereiro de 2009 e que estavam internados na totalidade nas unidades do referido hospital, com exceção das 
Unidades Pediátricas e do Serviço de Emergência, que inclui o Pronto-Socorro, o Pronto-Atendimento e as Retaguardas do Pronto-Socorro. Destes, 16 prontuários foram excluídos, pois os pacientes encontravam-se em morte encefálica e, desse modo, sem indicações para a realização de ressuscitação. Além disso, 58 prontuários não possuíam anotações referentes à PCR, portanto, também foram excluídos. A amostra compôs-se de 70 prontuários.

A coleta de dados foi realizada por uma aluna de graduação em Enfermagem no período de 1 de maio a 30 de junho de 2009 por meio da leitura desses prontuários. $\mathrm{O}$ instrumento utilizado para a coleta foi o modelo Utstein (Anexo 1), que enfatiza as variáveis: identificação do paciente, dispositivos preexistentes na PCR, condições clínicas antes e após o evento, causas imediatas de PCR, tentativa de RCP, ritmo inicial de PCR, horário dos eventos associados, drogas utilizadas e variáveis de seguimento e mortalidade.

Após a coleta dos dados, iniciou-se a comparação entre as anotações realizadas nos prontuários inclusos na pesquisa em relação às informações mencionadas no modelo Utstein.

O estudo foi aprovado pelo Comitê de Ética em Pesquisa da Instituição (CEP 0510/09).

\section{RESULTADOS}

No período do estudo, foram analisados 144 prontuários mas, apenas 70 prontuários entraram para a amostra, uma vez que 16 eram de pacientes com morte encefálica e em 58 deles não havia anotação referente à RCP. Desses 58 prontuários, 12 apresentaram-se em branco, sem informação alguma e em 46 deles havia apenas referências ao óbito e cuidados pós-morte.

Dos 70 prontuários constituintes da amostra, as anotações referentes à variável "Identificação", proposta no modelo Utstein, estavam presentes na totalidade e contemplaram nome, idade, sexo, registro hospitalar e diagnóstico de internação.

Em relação ao sexo, 30 (43\%) eram mulheres e 40 (57\%), homens, e a idade variou de 16 a 97 anos, com média de 61 anos. A faixa etária mais acometida pela PCR foi de 51 a 74 anos, respondendo por $50 \%$ dos casos, com desvio padrão de 17,32. Os itens leito, peso e altura não foram analisados.

Quanto ao diagnóstico de internação, a doença de base mais comum foi a insuficiência cardíaca descompensada ocorrida em dez pacientes (14\%), seguida de insuficiência renal crônica agudizada em sete dos casos $(10 \%)$ de infarto agudo do miocárdio em três dos casos $(4, \%)$ e outras causas em 40 pacientes $(72 \%)$.

Com relação aos dispositivos preexistentes ou em uso no momento da PCR, detectou-se que $25 \%$ dos pacientes possuíam de um a três dispositivos anteriormente à PCR e que $25 \%$ possuíam de três a quatro, com média de 2,9 e desvio padrão de 1,57.

Quanto às causas imediatas da PCR, em 65 prontuários $(92 \%)$ não havia informação referente a esse item. Nos demais prontuários, quatro $(5,7 \%)$ referiram-se à hipotensão, como causa imediata, e um caso $(1,4 \%)$ era referente a outras causas (Tabela 1).

Tabela 1 - Presença de anotações referentes às causas imediatas de PCR nos prontuários de pacientes com PCR seguida de óbito, nas unidades de internação. São Paulo, maio/junho de 2009.

\begin{tabular}{lrr}
\hline Causa imediata & $\mathbf{n}$ & $\mathbf{0}$ \\
\hline Hipotensão & 4 & 5,7 \\
Outras & 1 & 1,4 \\
Sem Anotação & 65 & 92,8 \\
\hline Total & 70 & 100 \\
\hline
\end{tabular}

No que se refere ao item "Tentativa de Ressuscitação", em $24(34,3 \%)$ dos 70 prontuários, havia anotação referente a esse item, porém com dados incompatíveis com o registro do modelo Utstein e, portanto, não participaram da amostra. Assim, verificou-se que dentre 46 prontuários, em $33(71,7 \%)$ não havia anotação referente à tentativa de ressuscitação. Em seis (13\%) deles, havia registro da não tentativa de ressuscitação, em um $(2,2 \%)$ da realização de compressão torácica, em um $(2,2 \%)$ realização de desfibrilação, em três $(6,5 \%)$ a obtenção de via aérea e em dois $(4,3 \%)$ a obtenção de via aérea associada à compressão torácica, conforme demonstrado na Tabela 2.

Tabela 2 - Presença de anotações referentes à tentativa de ressuscitação nos prontuários de pacientes com PCR, seguida de óbito nas unidades de internação. São Paulo maio/junho de 2009.

\begin{tabular}{lrr}
\hline Tentativa de RCP & $\mathbf{n}$ & $\mathbf{0}$ \\
\hline Não realizada & 6 & 13,0 \\
Compressões Torácicas & 1 & 2,2 \\
Desfibrilação & 1 & 2,2 \\
Obtenção de via Aérea & 3 & 6,5 \\
Obtenção de via Aérea e Compressões & 2 & 4,3 \\
Torácicas & & \\
Sem anotação & 33 & 71,7 \\
Total & 46 & 100 \\
\hline
\end{tabular}

Quanto ao ritmo inicial, a amostra foi composta de 64 prontuários, já que em seis pacientes, da amostra total (70 pacientes), não houve tentativa de ressuscitação. Em 26 $(40,6 \%)$ dos prontuários, havia anotação referente ao ritmo inicial da PCR e em 38 (59,3\%), não havia nenhuma informação a respeito. Dentre os 26 prontuários que apresentaram anotação referente ao ritmo, na maioria deles $(53,8 \%)$ foi registrado ritmo inicial assitolia (Tabela 3). 
Tabela 3 - Presença de anotações referentes ao ritmo inicial de PCR nos prontuários de pacientes com PCR, seguida de óbito nas unidades de internação. São Paulo, maio/junho, 2009

\begin{tabular}{lrr}
\hline Ritmo inicial & n & $\mathbf{\%}$ \\
\hline Assistolia & 14 & 53,8 \\
AESP & 6 & 23,0 \\
AESP seguida Assistolia & 4 & 15,4 \\
FV seguida AESP & 1 & 3,9 \\
FV seguida TV & 1 & 3,9 \\
\hline Total & 26 & 100 \\
\hline
\end{tabular}

Nos prontuários dos pacientes submetidos à RCP, no que diz respeito à variável "Hora dos Eventos", dos 64 prontuários analisados, em dez deles esta informação não estava presente $(15,6 \%)$. Nos 54 prontuários restantes, havia referência ao item "Parada Detectada", indicando o horário. Já quanto ao item "Parada Confirmada", em um prontuário foi anotado o horário dessa informação. Quanto ao item "RCP Iniciada", o horário do início de tal procedimento estava presente em 11 dos prontuários, o item "Via Aérea Obtida" em três, "1ª Desfibrilação" em três, "1 $1^{a}$ Dose de Epinefrina" em oito, "1 $1^{a}$ Dose de Atropina" em sete e "RCP Terminada" em sete.

Os dados da figura abaixo mostram que $50 \%$ dos prontuários apresentaram anotação de um a dois horários de realização de diferentes procedimentos na RCP, com média de 1,45 e desvio-padrão de 1,34.

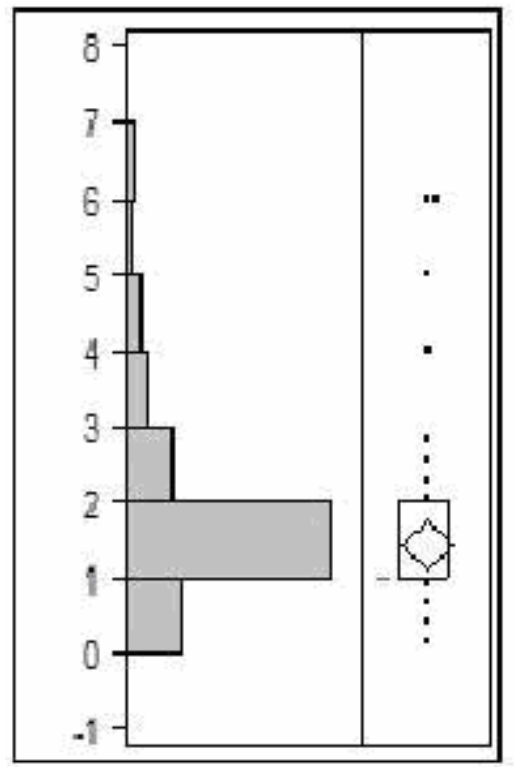

Figura 1 - Quantidade das anotações dos horários de realização de procedimentos de em pacientes com PCR seguida de óbito. São Paulo, maio/junho, 2009.

No que se refere ao "Retorno da Circulação Espontânea", não foi encontrada nenhuma informação a respeito na totalidade dos prontuários.
Quanto aos medicamentos utilizados durante a RCP, em $50 \%$ dos prontuários não havia registros sobre a dosagem ou nome do medicamento; em 25\% foi referida a utilização de apenas um medicamento durante a RCP, porém sem a dosagem, nos $25 \%$ restantes havia anotação referente a dois ou mais medicamentos, porém, também sem anotação de dosagem ou nome do medicamento, com média de 0,61 e desvio padrão de 1,08.

Nas variáveis de seguimento, 57 (89\%) dos prontuários apresentaram-se sem anotações referentes aos "Envolvidos na Reanimação". Em quatro (6\%) prontuários, foi mencionado apenas a participação de médico e em três $(5 \%)$ a participação médica e do enfermeiro. Em nenhum prontuário, foi feita referência ao número de médicos ou de enfermeiros com curso de Suporte Avançado de Vida em Cardiologia (SAVC).

\section{DISCUSSÃO}

No total de prontuários analisados, verificou-se que parte deles (51,4\%) não entrou para a amostra do estudo, já que não possuíam anotações referente a PCR, por se tratar de pacientes com morte encefálica, por estar em branco ou por apresentar anotações sobre apenas o óbito ou cuidados pós-morte. Este dado é de grande relevância, uma vez que mostra que as anotações referentes à PCR não contemplam dados significativos para a prestação do cuidado, bem como não cumprem com a exigência do Conselho Regional de Enfermagem.

Analisando a variável do modelo Utstein "Identificação" - comparada à análise realizada nos prontuários do estudo, verificou-se que sua anotação foi realizada de forma correta e impreterivelmente registrada. O item "Idade" e sua anotação são de extrema importância e vêm sendo estudado, a fim de se relacionar aos fatores de risco, prognóstico e às diferenças no tratamento ${ }^{(8)}$. Ademais, estudos atuais em PCR têm enfatizado cada vez mais dados epidemiológicos, como idade e doenças preexistentes ${ }^{(12)}$.

A faixa etária mais acometida foi acima de 60 anos e os diagnósticos de internação mais frequentes referiramse às doenças cardiovasculares. Assim como em outro estudo $^{(12)}$, a presença de doenças de base, no ambiente intra-hospitalar, mostra que esses pacientes podem ser de alto risco e registrar essa informação auxilia na preconização de procedimentos e atenção diferenciada a esse paciente ${ }^{(7)}$.

Quanto à presença de dispositivos preexistentes à PCR, observou-se a regularidade da anotação nos prontuários, pois em 100\% deles havia relato dos mesmos. Mas, é importante ressaltar que esses dados não foram registrados no momento da anotação referente à PCR, e sim em anotações anteriores, indicando que os dispositivos preexistentes, também, não foram corretamente descritos. 
Já no que se refere ao item "Causa Determinante da Parada", houve escassez de informações, uma vez que, em $94 \%$ dos prontuários, não havia esse registro. Estudos nos quais essa informação se fez presente, encontraramse a hipotensão e o infarto agudo do miocárdio como causas de PCR, que pioraram o prognóstico, após o evento, tanto em homens como em mulheres ${ }^{(13-15)}$, demonstrando a relevância da presença desse dado, tanto para nortear as intervenções a serem adotadas no decorrer do atendimento à PCR como para avaliar se estas trataram a causa imediata de PCR e se foram eficazes para tal.

No item, "Tentada Ressuscitação", em 33 (71,7\%) prontuários dos 46 da amostra, essa informação não se fez presente e quando mencionada, houve falta de informações, pois, uma vez realizada a tentativa de RCP, na maioria das vezes, não se fez menção às intervenções realizadas. Isso denota que há falhas nas anotações de enfermagem nessa situação e que as mesmas não refletem a prática realizada, podendo indicar má qualidade da assistência prestada.

Por ser a anotação uma atividade realizada pela equipe de enfermagem, e, por sua vez, é liderada pelo enfermeiro, que direciona e coordena a assistência ao paciente de forma individualizada e contínua, julga-se fundamental uma anotação clara e completa do atendimento prestado, considerando-se que a sistematização da assistência é um dos indicadores de qualidade na enfermagem ${ }^{(16)}$.

A falta de dados, também foi percebida no que diz respeito à variável "Ritmo Inicial da PCR"; em 38 prontuários essa informação não se fez presente. Nos prontuários em que essa existia (26), o ritmo de assistolia foi o mais frequentemente encontrado, seguido de AESP e AESP, seguida de assistolia. Esses dados são semelhantes aos encontrados em alguns estudos ${ }^{(5,17)}$ e divergem de outros $^{(2)}$. Provavelmente, as diferentes características das instituições e populações envolvidas nos estudos sejam responsáveis pelos diferentes achados ${ }^{(8)}$.

A variável "Hora dos Eventos" apresentou registro em $84 \%$ dos prontuários, que estavam incompletos, não contemplando os itens "Parada Confirmada", "RCP Iniciada", "Via Aérea Obtida", "1ª Desfibrilação", "1ª Dose de Epinefrina", "1 $1^{a}$ Dose de Atropina" e "RCP Terminada". Neste aspecto, torna-se importante ressaltar que falhas relacionadas a estas informações podem indicar falhas no atendimento. A situação torna-se mais grave em se tratando de um hospital universitári onde essas intervenções e suas respectivas anotações deveriam ser rigorosamente incentivadas, exercitadas e realizadas.

Em relação à variável "Drogas Utilizadas", em 32 $(50 \%)$ prontuários não houve anotação e, quando presente, com pouca referência à dosagem do medicamento. Estudos mostram a importância de se realizar as anotações referentes a esse item, a fim de se obter resposta de sua eficácia terapêutica durante a RCP, bem como discutir a implementação de novos agentes medicamentosos ${ }^{(12)}$. Ademais, levando-se em consideração que a terapêutica medicamentosa na RCP intra-hospitalar é largamente utilizada, o fato das anotações dos medicamentos utilizados não serem completas pode acarretar falsas interpretações ou dúvidas sobre os acontecimentos e as intervenções na tentativa de restaurar as funções vitais do paciente.

Nas variáveis de seguimento, em $89 \%$ dos prontuários não havia anotação referente aos profissionais envolvidos na RCP e ao treinamento destes em manobras de SAVC. A literatura mostra que as anotações que dizem respeito ao conjunto de dados da equipe de atendimento, bem como o registro dos profissionais que participaram da RCP e sua respectiva função são insuficientes e dados relevantes não são registrados ${ }^{(18)}$.

A comunicação na área de emergência, no que se refere às anotações de enfermagem, merece amplos estudos, pois afeta diretamente a qualidade dos atendimentos prestados. Esses registros são importantes para fins éticos e legais, e visam a identificar a presença de um líder durante o atendimento, bem como de facilitadores da comunicação entre a equipe, favorecendo discussões e avaliações sobre as intervenções realizadas e melhorando a qualidade e o desempenho para os próximos atendimentos ${ }^{(18-19)}$.

Alguns estudos sugerem a viabilidade e utilização do modelo Utstein, pois este pode contribuir para a melhoria da documentação do atendimento à PCR, para a capacitação de pessoal e para a realização de estudos de sobrevida e outras pesquisas nesta área, melhorando as práticas de atendimento ${ }^{(8,18)}$.

A coleta sistematizada de dados possibilita a avaliação da qualidade dos serviços de emergência. O modelo Utstein necessita ser aprimorado e adaptado às diversas realidades, pois exige informações sobre a PCR e as intervenções durante a RCP. Estudos sugerem a utilização de um registro mais reduzido ${ }^{(8)}$, uma vez que a justificativa frequente entre os profissionais de enfermagem é a falta de tempo para realizar as anotações descritivas, diante das rotinas de trabalho e da elevada quantidade de procedimentos assistenciais ${ }^{(18)}$.

Neste estudo, assim como em outros ${ }^{(8,18-19)}$ os registros apresentaram-se incompletos, reforçando a necessidade de melhorá-los e, consequentemente, da capacitação dos profissionais de enfermagem, a fim de aprimorar a documentação, sendo o modelo Utstein uma ferramenta para este fim. Dessa forma, com este registro, é possível retratar o trabalho, refletindo fidedignamente a qualidade da prática, melhorar a organização das unidades hospitalares e realizar novos estudos em RCP.

\section{CONCLUSÃO}

Com base nos resultados deste estudo, concluir-se que 
os registros das manobras de RCP não são realizados de maneira cronológica e seqüencial, e quando presentes, as informações são escassas. Quando comparados ao modelo Utstein, observou-se um grande número de itens não preenchidos ou dados insuficientes, constatando que os registros quase sempre não contemplam informações relevantes.

O modelo Utstein favorece a anotação sequencial dos eventos e do atendimento prestado, evitando que

\section{REFERÊNCIAS}

1. Aehlert B. ACLS, advanced cardiac life support: emergências em cardiologia: suporte avançado de vida em cardiologia: um guia para estudo. 3a ed. Rio de Janeiro: Elsevier; 2007.

2. Cooper S, Cade J. Predicting survival, in-hospital cardiac arrests: resuscitation survival variables and training effectiveness. Resuscitation. 1997;35(1):17-22.

3. Resuscitation from cardiopulmonary arrest. Training and organization. A report of the Royal College of Physicians. J R Coll Physicians Lond. 1987;21(3):175-82.

4. Moreira DM, Mariante Neto G, Oliveira MW, Alves LB, Adamatti LCC, Trotta EA, Vieira SRR. Estudo retrospectivo de sobrevida de pacientes submetidos à reanimação cardiorrespiratória em unidade de tratamento intensivo. Arq Bras Cardiol. 2002;78(6):545-52.

5. Bartholomay E, Dias FS, Torres FA, Jacobson P, Mariante A, Wainstein R, et al. Impacto das manobras de reanimação cardiorrespiratória cerebral em um hospital geral: fatores prognósticos e desfechos. Arq Bras Cardiol. 2003;81(2):18295.

6. Cummins RO, Chamberlain D, Hazinski MF, Nadkarni V, Kloeck W, Kramer E, et al. Recommended guidelines for reviewing, reporting, and conducting research on in-hospital resuscitation: the in-hospital "Utstein style". American Heart Association. Circulation. 1997;95(8):2213-39.

7. Huang CH, Chen WJ, Ma MH, Chang WT, Lai CL, Lee YT. Factors influencing the outcomes after in-hospital resuscitation in Taiwan. Resuscitation. 2002;53(3):265-70.

8. Cavalcante TMC, Lopes RS. O atendimento à parada cardiorrespiratória em unidade coronariana segundo o protocolo Utstein. Acta Paul Enferm. 2006;19(1):7-15.

9. Zanini J, Nascimento ERP, Barra DCC. Parada e reanimação cardiorrespiratória: conhecimentos da equipe de enfermagem em Unidade de Terapia Intensiva. Rev Bras Ter Intensiva. 2006;18(2):143-7.

10. Passador MB, Canavezi CM. Anotações de enfermagem: aspectos éticos e legais. São Paulo: Demais Editora; 2008.

11. Cianciarullo TI, Gualda DMR, Melleiro MM, Anabuki MH. informações sejam perdidas e cria um banco de dados confiável, permitindo que os procedimentos sejam revistos, o que pode colaborar em futuros atendimentos e estudos posteriores.

A escassez de estudos relacionados às anotações de enfermagem durante o atendimento à PCR é um problema presente no mundo, o que reforça a importância da implementação de protocolos validados que viabilizam o registro fidedigno de informações sobre o atendimento.

Sistema de assistência de enfermagem: evolução e tendências. São Paulo: Ícone; 2001.

12. Gullo A. Cardiac arrest, chain of survival and Utstein style. Eur J Anesthesiol. 2002;19(9):624-33.

13. Pell JP, Sirel J, Marsden AK, Cobbe SM. Sex differences in outcome following community-based cardiopulmonary arrest. Eur Heart J. 2000;21(3):329-44.

14. Wigginton JG, Pepe PE, Bedolla JP, De'Tamble LA, Atkins JM. Sex-related differences in the presentation and outcome of out-of-hospital cardiopulmonary arrest: a multiyear, prospective, population-based study. Crit Care Med. 2002;30(4 Suppl):S131-6.

15. Di Bari M, Chiarlone M, Fumagalli S, Boncinelli L, Tarantini F, Ungar A, et al. Cardiopulmonary resuscitation of older, inhospital patients: immediate efficacy and long-term outcome. Crit Care Med. 2000;28(7):2320-5.

16. Brasil. Conselho Federal de Enfermagem. Resolução COFEN n ${ }^{\circ} 293$, de 21 de setembro de 2004. Fixa e Estabelece Parâmetros para o Dimensionamento do Quadro de Profissionais de Enfermagem nas Unidades Assistenciais das Instituições de Saúde e Assemelhados. [citado 2010 Jun 22]. Disponível em: http:/ /www.portalcofen.gov.br/ Site $/ 2007 /$ materias.asp?ArticleID=7121\&sectionID $=34$.

17. Timerman A, Sauaia N, Piegas LS, Ramos RF, Gun C, Santos ES, Bianco ACM, Sousa JEMR. Fatores prognósticos dos resultados de ressuscitaçäo cardiopulmonar em um hospital de cardiologia. Arq Bras Cardiol. 2001;77(2):142-60.

18. Boaventura AP, Araújo IEM. Registro do atendimento da parada cardiorrespiratoria no ambiente intra-hospitalar: aplicabilidade de um instrumento. Revista Gaúch Enferm. 2006;27(3):434-42.

19. Resende CCF, Santiago GR, Rocha ADM, Gresta MM. Fatores determinantes do sucesso na interação da equipe de atendimento à parada cardiorrespiratória. Rev Enf Hosp On line 2009;1(1):13-4. [citada 2010 Set 11]. Disponíel em: http://www.enf.ufmg.br/ojs/index.php/reonline/article/ viewFile $/ 13 / 7$ 
Anexo 1

\section{REGISTRO DO ATENDIMENTO A PCR}

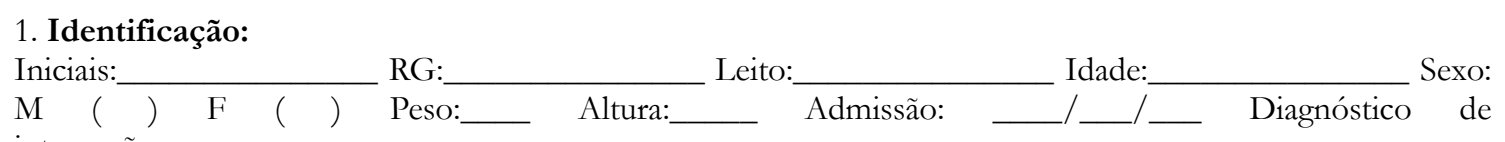
internação:

\section{Dispositivos preexistentes na parada}

() Nenhum () Acesso venoso: Central () Periférico ()

() Drogas vasoativas () Drogas antiarritmicas

() Outras: () Intubação ( ) Ventilação mecânica () Cateter arterial

() Marcapasso: Transcutâneo () Transvenoso ()

() Swan-Ganz () BIA

- Causas imediatas

() Arritmia () hipotensão () Respiratória () Metabólica () IAM ou isquemia

() Desconhecida

- Tentada ressuscitação:

() Sim (marque os realizados): () Via aérea ( ) Compressão torácica

() desfibrilação

() Não () achado morto ( ) considerado fútil

- Ritmo inicial ( No caso de mais de um ritmo, enumere-os)

( ) FV ( ) TV ( ) AESP ( ) Bradicardia ( ) Assistólia

\section{Hora dos eventos}

Parada detectada:

Parada confirmada:

RCP iniciada:

Via aérea obtida:

- Circulação espontânea:

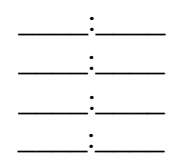

() retornou, se sim

() Nunca atingida

() RCE não sustentada: () $<20$ min. () $>20$ min $<24$ h () $>24$ h

4. Drogas utilizadas (mg/amp/vol.)

Epinefrina:

Procainamida:

Magnésio: $1^{\mathrm{a}}$ Desfibrilação

$1^{\text {a }}$ Dose de epinefrina:

$1^{\mathrm{a}}$ Dose de atropina

RCP terminada
Amiodarona: Gluc. Ca:

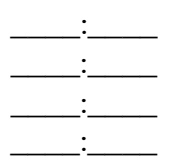

Lidocaína: Bic. de sódio:

\section{Variáveis de seguimento}

- Envolvidos na reanimação: () Médico () Enfermeiro () Auxiliar de Enf.

- $\quad \mathrm{N}^{\mathrm{o}}$ de médicos com ACLS:

- $\mathrm{N}^{\mathrm{o}}$ de enfermeiros com ACLS:

- Quando acordou: data:

() alta hora

- Seguimento no hospital: () alta

- Destino: () Outro hospital ( ) Casa

- Glasgow na alta:

( ) Morte no hospital:

Hora:

Data:

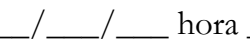
hora

() Suporte retirado () Morte cerebral () Doador

Principal causa do óbito:

- Outras tentativas de reanimação? (Se há mais de 24 horas da atual) () Sim () Não

Quantas?

Datas:

- Dados anotados no prontuário referente à PCR ( ) Completos ( ) Incompletos

Informações adicionais: 